\title{
Assessing Demographic Factors Related to Maternal Mortality in Tehran Province, Iran from 2008 to 2011
}

\author{
Fereshteh Farzianpour ${ }^{1 *}$, Abbas Rahimi Foroushani2 ${ }^{*}$, Nasrin Changizi ${ }^{3}$, \\ Khatere Ramezani ${ }^{1}$ \\ ${ }^{1}$ Department of Health, Management and Economics, School of Public Health, Tehran University of Medical \\ Sciences, Tehran, Iran \\ ${ }^{2}$ Department of Epidemiology and Biostatistics, Tehran University of Medical Sciences, Tehran, Iran \\ ${ }^{3}$ Department of Health for Maternal Health, Tehran, Iran \\ Email: farzianp@sina.tums.ac.ir, farzianp2@yahoo.com, ${ }^{*}$ rahimifo@tums.ac.ir, n.changizi@yahoo.com, \\ ramezani@yahoo.com
}

Received 23 January 2015; accepted 1 March 2015; published 10 March 2015

Copyright (C) 2015 by authors and Scientific Research Publishing Inc.

This work is licensed under the Creative Commons Attribution International License (CC BY).

http://creativecommons.org/licenses/by/4.0/

(c) (i) Open Access

\section{Abstract}

The rate of maternal mortality due to complications of pregnancy and delivery is one of the most significant indicators showing the development state of countries. The purpose of the present study is to assess important indicators of maternal health and predisposing factors of maternal mortality in Tehran province from 2008 to 2011. The present study is a case-control one. All mothers who had lost their life $(n=113)$ were selected through census and survived mothers $(n=$ 327) through randomized stratified sampling. Statistical analysis was performed using SPSS V.22, $\mathrm{X}^{2}$ test, Fishers exact test and Logistic regression. The rate of maternal mortality was the highest $(29.2 \%)$ in 2009 and the lowest $(20.4 \%)$ in 2011 . Variables type of maternity hospital $(\mathrm{P}$-value $=$ 0.036), maternal education ( $P$-value $<0.001$ ), husband's education $(P$-value $<0.001$ ) had a significant relation to maternal mortality. Logistic regression analysis showed that there is a relationship between the education level of the husband and maternal mortality. Considering the factors affecting maternal mortality, promoting hospital services, improving skills and knowledge of doctors, midwives and nurses and strengthening educational programs for the illiterate are the most effective measures to reduce maternal mortality.

\section{Keywords}

Assessing, Demographic Factors, Maternal Mortality, Tehran Province, Iran

\footnotetext{
${ }^{*}$ Corresponding authors.
}

How to cite this paper: Farzianpour, F., Foroushani, A.R., Changizi, N. and Ramezani, K. (2015) Assessing Demographic Factors Related to Maternal Mortality in Tehran Province, Iran from 2008 to 2011. Health, 7, 308-315. 


\section{Introduction}

The rate of maternal mortality due to complications of pregnancy and delivery is one of the most significant indicators showing the development state of countries. The reason for the choice of this indicator as one of the most apparent factors representing development is the effect of social and economic factors on the increase or decrease of maternal mortality. This indicator is dependent on women's literacy status, rural road network, access to the midwifery and delivery emergency, cost of health services, the existence of telecommunication networks, household income, and...

In fact, health services constitute only part of the factors affecting the decrease in women's mortality. In most developing countries mortality due to the complications of pregnancy and delivery is regarded as the first reason for the death and disability of women aged 15 - 49 years and also the reason for at least 18 percent of the diseases affecting this age group [1].

Improvement in the health status of mothers following the decrease in poverty has been considered as one of the prerequisites of development. To measure maternal mortality rate, an indicator named Maternal Mortality Ration (MMR) is used, showing the rate of maternal mortality due to complications of pregnancy and delivery per 100,000 live deliveries (Figure 1). The indicator MMR shows the women general health status in the society [2]. Investment on the better health status of mothers not only improves the health status of the mother and her family but also increases the number of working women, considering workforce, and so the economic state of the society and country. Untreated delivery and pregnancy complications cause $10-20$ million women yearly to lose the ability to support themselves and their families [3].

Improving maternal health is viewed as one of the most important commitments of any country. Based on the latest report of WHO, Islamic Republic of Iran is one of the countries which have been successful in achieving the fifth goal of Millennium Development. According to the national surveillance system for maternal mortality, maternal mortality ratio in the last ten years can be seen in the chart below. The MMR rate chart based on data collected in 2002-2012 19/5 declined [2] [4] Figure 2.

The most common cause of maternal death in 2011 in Iran as reported.

In 60 to 80 percent, maternal deaths are due to hemorrhage, hard labor, high blood pressure, infections and complications of Unsafe abortions, noticeable percent of which occur after childbirth and about 78 percent of it is related to 24 to 48 first hours after childbirth [4]-[9] Figure 3. The purpose of the present study is assessing demographic factors related to maternal mortality in the province of Tehran-Iran (2008-2011).

\section{Methods}

The present study is a case-control one in which the women not survived (on child birth or during pregnancy) constitute the subject group and those who have had a successful delivery the control group. This study was approved by the Ethical Committee of Tehran University of Medical Sciences (TUMS) in 2012/6/10. About the nature and purpose of the study was explained to the participants. The subjects signed the informed consent form to participle in the study. Considering the system governing the maternal mortality in Iran which requires that maternal mortality be reported immediately, by six weeks after delivery the subjects, i.e. the women not

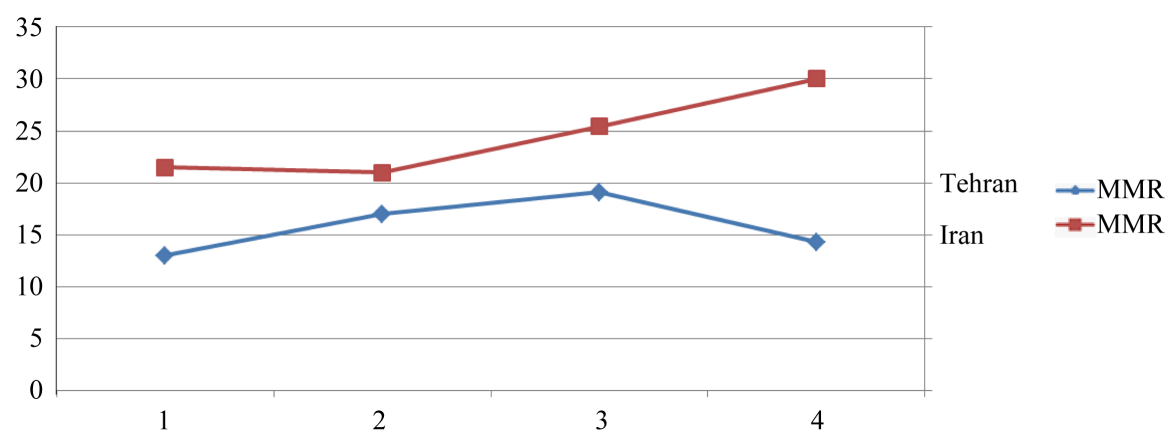

Figure 1. Diagram of comparing maternal mortality ratio in Tehran and Iran. Maternal mortality ratio per 100 thousand live births for the years 2008-2011 respectively was $21.5,21$, 25.4 and 30. MMR was the highest in 2008 with 30 per 100 thousand live births and the lowest in 2009 with 21 per 100 thousand live births. 


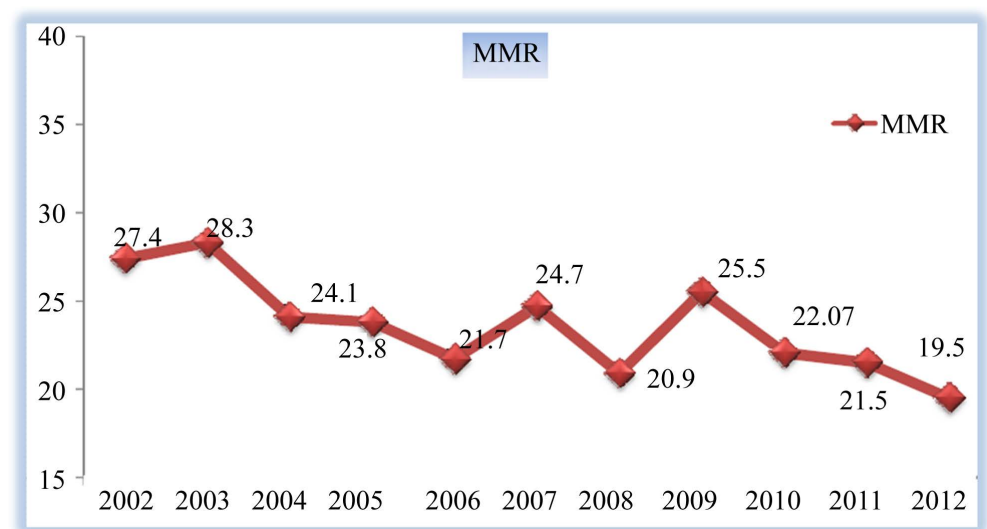

Figure 2. The MMR rate chart based on data collected in 2002-2012 19/5 declined.

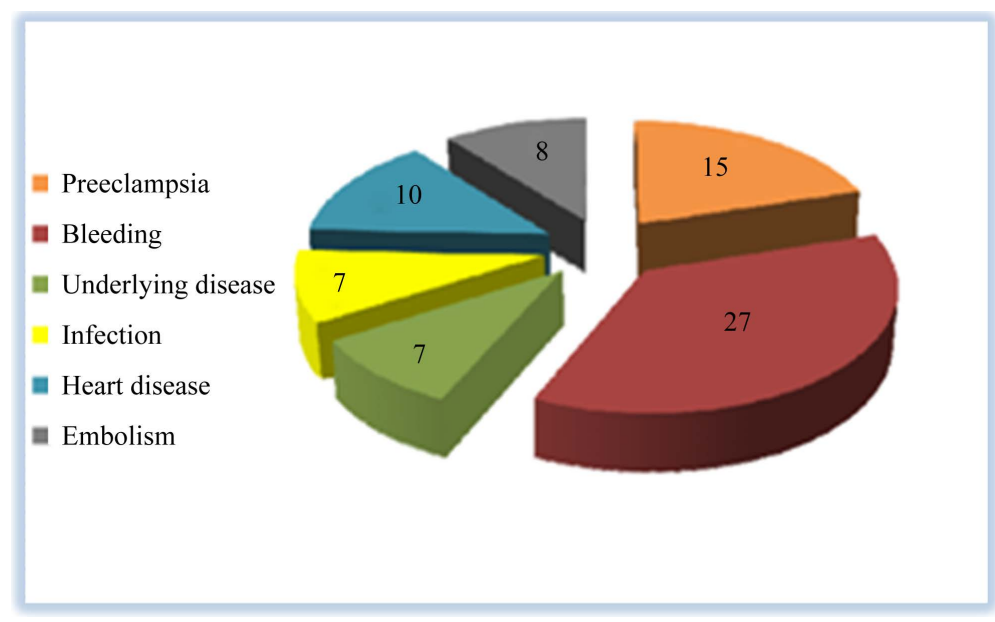

Figure 3. The most common cause of maternal death in 2011 in Iran.

survived on child birth or during pregnancy in 2008, 2009, 2010 and 2011 were selected using the information existing in the family health department in medical sciences universities of Tehran, Shahid Beheshti and Iran (n $=113$ ) through census and the control group (survived mothers) were selected from those who had given birth in hospitals in the province of Tehran from 2008-2011 ( $\mathrm{n}=327)$ through classified randomized sampling.

The statistical analysis was done using soft ware SPSSV. 22 and tests $\mathrm{x}^{2}$, t-test, careful Fisher test and Logistic regression.

\section{Results}

Findings of the study indicated that $24.8 \%$ (28) , 29.2\% (33), 25.7\% (29) and 20.4\% (23) of the subject group in years 2008, 2009, 2010 and 2011 respectively and $23.2 \%$ (76), $27.5 \%$ (90), 25.4\% (83) and $23.9 \%$ (78) of the control group in 2008, 2009, 2010 and 2011 respectively had given birth (Table 1).

$\mathrm{X}^{2}$ test showed that two groups were the same concerning the year when delivery was done. The results also indicated that of the women who had not survived73.5\%, 22.1\% and 4.4\% were 20 - 34 years old, 35 or above and under 18 respectively, but $\mathrm{X}^{2}$ test didn't show any significant relationship between the two groups (P-value $=0.442$ ). Most of the women under the study in the two groups (subject and control) lived in urban areas and also most of them, i.e. (96.6\% of the subjects and $97.2 \%$ of the control group) had given birth in hospital and the difference between the two groups was not statistically significant $(\mathrm{P}-$ Value $=0.289)$.

$51.2 \%, 25 \%, 17.9 \%$ and $6 \%$ of the subjects and $38 \%, 37.4 \%, 13.4 \%$ and $11.2 \%$ of the control group had given birth in teaching and treatment hospitals, private hospitals and social security hospitals respectively. 
Table 1. Comparison of the relative frequency distribution of subjects in the two groups subject and control in the province of Tehran-Iran from 2008-2011.

\begin{tabular}{|c|c|c|c|c|c|c|}
\hline \multirow{2}{*}{ Variable } & \multirow{2}{*}{ Group } & \multicolumn{2}{|c|}{ Subject } & \multicolumn{2}{|c|}{ Control } & \multirow{2}{*}{ Result of the tes } \\
\hline & & Number & Percent & Number & Percent & \\
\hline \multirow{4}{*}{ Year of delivery } & 2008 & 28 & 24.8 & 76 & 23.2 & \multirow{4}{*}{$\begin{array}{c}\mathrm{X}^{2}=6.19 \\
\text { P-value }=0.892\end{array}$} \\
\hline & 2009 & 33 & 29.2 & 90 & 27.5 & \\
\hline & 2010 & 29 & 25.7 & 83 & 25.4 & \\
\hline & 2011 & 23 & 20.4 & 78 & 23.9 & \\
\hline \multirow{3}{*}{$\begin{array}{l}\text { Age at the time of } \\
\text { delivery }\end{array}$} & $\leq 18$ & 5 & 4.4 & 26 & 8 & \multirow{3}{*}{$\begin{array}{c}\mathrm{X}^{2}=1.631 \\
\text { P-value }=0.442\end{array}$} \\
\hline & $18-34$ & 83 & 73.5 & 234 & 71.6 & \\
\hline & $\geq 35$ & 25 & 22.1 & 67 & 20.5 & \\
\hline \multirow{2}{*}{ Place of living } & City & 94 & 83.2 & 249 & 76.1 & \multirow{2}{*}{$\begin{array}{c}X^{2}=2.241 \\
\text { P-value }=0.120\end{array}$} \\
\hline & Town/village & 19 & 16.8 & 78 & 23.9 & \\
\hline \multirow{4}{*}{ Place of delivery } & Home & 2 & 2.3 & 1 & 0.3 & \multirow{4}{*}{$\begin{array}{l}\text { Fisher exact test } \\
\mathrm{P} \text {-value }=0.289\end{array}$} \\
\hline & On the way & 1 & 1.1 & 7 & 2.1 & \\
\hline & Delivery facilities & 0 & 0 & 1 & 0.3 & \\
\hline & Hospital & 84 & 96.6 & 318 & 97.2 & \\
\hline \multirow{4}{*}{ Kind of hospital } & Treatment-teaching & 43 & 51.2 & 122 & 38 & \multirow{4}{*}{$\begin{array}{c}X^{2}=8.520 \\
\text { P-value }=0.036\end{array}$} \\
\hline & Treatment & 21 & 25 & 120 & 37.4 & \\
\hline & Private & 15 & 17.9 & 43 & 13.4 & \\
\hline & Social & 5 & 6 & 36 & 11.2 & \\
\hline \multirow{5}{*}{$\begin{array}{l}\text { Educational level } \\
\text { of the mother }\end{array}$} & Illiterate & 16 & 14.2 & 6 & 1.8 & \multirow{5}{*}{$\begin{array}{c}X^{2}=35.002 \\
\text { P-value }<0.007\end{array}$} \\
\hline & Elementary & 16 & 14.2 & 22 & 6.7 & \\
\hline & Secondary & 22 & 19.5 & 85 & 26 & \\
\hline & Diploma & 44 & 38.9 & 167 & 51.1 & \\
\hline & Higher & 15 & 13.3 & 47 & 14.4 & \\
\hline \multirow{5}{*}{$\begin{array}{c}\text { Husband's } \\
\text { educational level }\end{array}$} & Illiterate & 13 & 11.5 & 9 & 2.8 & \multirow{5}{*}{$\begin{array}{c}\mathrm{X}^{2}=37.626 \\
\text { P-value }<0.001\end{array}$} \\
\hline & Elementary & 14 & 12.4 & 16 & 4.9 & \\
\hline & Secondary & 29 & 25.7 & 54 & 16.5 & \\
\hline & Diploma & 41 & 36.3 & 188 & 57.5 & \\
\hline & Higher & 16 & 14.2 & 60 & 18.3 & \\
\hline \multirow{2}{*}{ Health insurance } & Yes & 78 & 69 & 208 & 63.6 & \multirow{2}{*}{$\begin{array}{c}X^{2}=1.084 \\
\text { P-value }=0.298\end{array}$} \\
\hline & No & 35 & 31 & 119 & 36.4 & \\
\hline \multirow{2}{*}{ Type of Citizenship } & Iranian & 99 & 87.6 & 280 & 85.6 & \multirow{2}{*}{$\begin{array}{c}\mathrm{X}^{2}=0.277 \\
\text { P-value }=0.599\end{array}$} \\
\hline & Non-Iranian & 14 & 12.4 & 47 & 14.4 & \\
\hline $\begin{array}{l}\text { Immigration } \\
\text { certificate }\end{array}$ & Yes & 5 & 35.7 & 21 & 45.7 & $\begin{array}{c}X^{2}=0.432 \\
\text { P-value }=0.511\end{array}$ \\
\hline
\end{tabular}

$\mathrm{X}^{2}$ test showed that there was no statistically significant difference between the two groups (P-Value $=0.036$ ). Considering the education level of the mothers and their husbands, there was no statistically significant difference between the two groups. The education level of the survived pregnant women and their husbands was higher than that of the not survived women and their husbands (P-Value $<0.001$ ).

Considering medical insurance, the kind of citizenship and immigration certificate, there was no statistically significant difference between the two groups (Table 1). In order to study the effect of various factors on probability of death in pregnancy, logistic regression was used. The results showed that chance of death in pregnant women whose husbands were illiterate or had primary education was 3.8-folds the risk of death in women that their husbands had a high school education or higher, so that OR = 3.8 CI 95\% (1.076 - 13.546) and because this 
distance does not have 1 , OR is significant.

Also, the chance of death in pregnant women with underlying disease was 5-folds of death risk among women who did not have an underlying disease, such that the OR = 5.03 CI 95\% (2.776 - 9.119) and because this distance does not have 1 , OR is significant.

The results showed that chance of death in pregnant women who had a vaginal delivery was $0 / 33$ folds the women who had cesarean section $0 / 33$, so that OR $=0.33$ CI $95 \%(0.15-0.73)$, and since the distance does about gestational age , death risk in women with gestational age 6 - 28 weeks was 3/36 folds the gestational age of 42 - 28 weeks, so that OR = 3.36 CI 95\% (1.209 - 9.341), and since the distance does not have 1, OR is significant.

Not have 1, OR is significant (Table 2).

\section{Discussion}

Based on the findings of the study the rate of maternal mortality in 100,000 live births in 2008-2011 were (13, 17, 19.1, 14.3) respectively. The rate of maternal mortality per 100 live births in 2009 (19.1) was the highest and in 2011 (13) the lowest [10]-[13].

In this study a relationship was found between the variables, kind of the hospital where delivery had been done (P-Value $=0.036)$, the mother's level of education (P-Value $<0.001)$ on one side and the mother's death on the other side. No relationship was found between the mother's age at the time of delivery, place of living, place of delivery, having medical insurance, type of citizenship and the state of immigration certificate on one side and the mother's death on the other side.

Our study was demographic factors related to maternal mortality in Tehran Province-Iran during 2008 to 2011. All data selected using the information existing in the family health department in medical sciences universities of Tehran, Shahid Beheshti and Iran. In this study we had Limitations as Incompleteness of records, insufficient cooperation and coordination of hospital personnel, pregnant mothers death due to causes non-related to pregnancy and residence of mothers died in a province other than Tehran that these problems have been resolved. The results of the present study indicated that the most percentage of the participants in the study (both the subjects and the control group) were in the age group 18 - 34. In the age group below 18, there were 5 cases of death.

Table 2. Logistic regression analysis of variables in the control group.

\begin{tabular}{|c|c|c|c|c|c|c|}
\hline \multirow{2}{*}{ Variables } & \multirow{2}{*}{$\mathrm{B}$} & \multirow{2}{*}{ S.E. } & \multirow{2}{*}{ P Value } & \multirow{2}{*}{ OR } & \multicolumn{2}{|c|}{ 95\% C.I. for } \\
\hline & & & & & Upper & Lower \\
\hline Number of pregnancy 1 & -0.681 & 0.604 & 0.260 & 0.506 & 1.655 & 0.155 \\
\hline Number of pregnancy 2 & -0.939 & 0.549 & 0.087 & 0.391 & 1.147 & 0.133 \\
\hline Number of pregnancy 3 & -0.776 & 0.551 & 0.159 & 0.460 & 1.354 & 0.156 \\
\hline Pregnancy age & 1.212 & 0.522 & 0.020 & 3.361 & 9.341 & 1.209 \\
\hline Hospital type of delivery & -0.197 & 0.354 & 0.578 & 0.821 & 1.643 & 0.410 \\
\hline Spouse education 1 & 1.340 & 0.646 & 0.038 & 3.818 & 13.546 & 1.076 \\
\hline Spouse education 2 & 0.607 & 0.390 & 0.119 & 1.836 & 3.941 & 0.855 \\
\hline Spouse education 3 & 0.335 & 0.542 & 0.537 & 1.398 & 4.046 & 0.483 \\
\hline Mother education 2 & -0.209 & 0.380 & 0.583 & 0.812 & 1.709 & 0.385 \\
\hline Number of abortion & 0.322 & 0.406 & 0.428 & 1.379 & 3.056 & 0.623 \\
\hline Infection with underlying disease & 1.616 & 0.303 & 0.000 & 5.032 & 9.119 & 2.776 \\
\hline Delivery agent & 0.457 & 0.506 & 0.367 & 1.580 & 4.262 & 0.585 \\
\hline Intentionality of pregnancy & 0.057 & 0.392 & 0.885 & 1.058 & 2.283 & 0.491 \\
\hline Delivery type & -1.116 & 0.410 & 0.006 & 0.327 & 0.731 & 0.147 \\
\hline Appropriate prenatal care & -0.225 & 0.310 & 0.469 & 0.799 & 1.467 & 0.435 \\
\hline
\end{tabular}

1. Illiterate, Elementary; 2. Secondary and Diploma; 3. Diploma and Higher. 
In a study conducted by khajeyian et al. (2011) 10 percent of the mothers were above 35 years of age and there was no maternal death concerning women below 18 [9]. Investigating the Factors related to the death of pregnant women in America indicated that the rate of maternal mortality was higher in women aged 35 or more than that in other age groups and in women above 40 the rate of death was four times as many as women aged 30 - 34 [12]. The result of another study in Province of Kordestan showed that there was no death in age group below 18 and the lowest rate of maternal mortality (18.2\%) was related to the women aged 35 or more [13]. While in the study related to maternal mortality in developed countries most of the deaths had happened to women above 35 [12]-[14].

Concerning the relationship between the place of residence and maternal death , although based on the findings of the study the rate of maternal death in women living in cities was twice as many as that in women living in villages (83.2\% versus $16.8 \%) \mathrm{x}^{2}$ test didn’t show a significant difference between the subject and control groups (P-value $=0.120$ ). In a study carried out in Mashhad 61.5\% of the mothers who had not survived lived in small towns and villages and 38.5\% in cities [15]. Another study done by abdollahipour and et al. found (2010) the rate of maternal death in women living in rural areas (35.08 per 100.000 live births) was higher than that in women living in urban areas (24.75) [16], The results of studies conducted by Golami Taromsary et al. [8], and Arshin Chi in 2008 and 2009 respectively Indicated that there was no statistically significant difference between the death percent women living in urban areas and those living in rural ones (15.8) [16] [17].

It seems that the reason why there was no significant difference between the two groups in the present study can be the access of people living in villages near Tehran to optimal health services, especially pregnancy care services and also because they gave birth in hospital not at home; There was no significant difference between the two groups considering the place of giving birth $(\mathrm{P}$-value $=0.289)$.

The results of the study corresponds to those of the studies conducted by Montazeri et al. (2008) in Kermanshah and Najaya et al. (2000) in Japan [18] [19]. In the present study, concerning the hospital where delivery is done, $\mathrm{X}^{2}$ test showed that there is a significant difference between the two groups, control and subject group. 51 . \% of the subject group and $38 \%$ of the control group had given birth in teaching and treatment hospitals. In the report on the performance and achievements of the maternal care system of the country in 2012, 39\% of the deliveries leading to death of the mothers had taken place in teaching hospitals, $28 \%$ in treatment hospitals, $10 \%$ in private hospitals, $10 \%$ in charity hospitals, $1 \%$ in hospitals of other organizations and in $10 \%$ kind of the hospital was unknown [20]. These results are correspondent to the results of the present study.

Concerning the mother's level of education, there was no statistically significant difference between the two groups, (P-value < 0.001).

In a study by MohammadiNia et al. (2013) the rate of maternal death in illiterate women was higher [21]. The results of the present study correspond to those reached by Emami Afshar et al. (2010) who showed the high rate of illiteracy in mothers not survived represents the important role of literacy in improving the health level of mothers [22]-[26]. Concerning the husband's level of education $\mathrm{X}^{2}$ test showed that there is a significant difference between the two groups (P-value $<0.001$ ), Also, findings of the study conducted by Farrokh Eslamlo et al. (2007) corresponds to those of the present study [7].

Since a considerable number of Afghanian people live in Tehran, the relationship between maternal death and the nationality (Iranian and non-Iranian) was studied, but the result of $\mathrm{X}^{2}$ test showed that the difference between the two groups was not significant.

Considering the fact that $90 \%$ of the pregnancies in the province is related to the age group 18 - 34, it seems maternal death in each age group is dependent on the number of pregnancies in that age group and the incidence of the highest maternal mortality rate in the age group. In addition, the increase in access to midwifery services and decrease in both fertility and pregnancy in risk ages, increase in access to modern and safer ways to prevent pregnancy decreases the number of unwanted pregnancies in risk ages.

\section{Conclusions}

The results showed that chance of death in pregnant women whose husbands were illiterate or had primary education was 3.8-fold the risk of death in women that their husbands had a high school education or higher. Also the chance of death in pregnant women with underlying disease was 5-fold of death risk among women who did not have an underlying disease. The results showed that chance of death in pregnant women who had a vaginal delivery was $0 / 33$ folds the women who had cesarean section. about gestational age, death risk in women with 
gestational age 6 - 28 weeks was 3/36 folds the gestational age of 28 - 42 weeks.

It seems that intervention in improving the quality of hospital services has a significant effect on the reduction of the number of maternal deaths and since more than $99 \%$ of the deliveries take place in hospitals of the province, it is necessary to pay attention to hospital services and the part they play in maternal death.

\section{Acknowledgements}

This article is a part of a MPH thesis entitled "Assessing Demographic Factors Related to Maternal Mortality in Tehran Province-Iran from 2008 to 2011" that has been supported by Tehran University of Medical Sciences, School of Health. The authors thank all those who have helped researchers at all stages of the project.

\section{References}

[1] Agan, T.U. and Archibong, E.L. (2010) Trends in Maternal Mortality at the University of Calabar Teaching Hospital, Nigeria, 1999-2009. International Journal of Women's Health, 2249-2254.

[2] Blanc, A.K., Winfrey, W. and Ross, J. (1993) New Findings for Maternal Mortality Age Patterns: Aggregated Results for 38 Countries World Health Organization. International Statistical Classification of Diseases and Related Health Problems, 10th Edition, WHO, Geneva, 141.

[3] Bodker, B., Hvidman, L., Weber, T., Moller, M., Aarre, A., Nielsen, K.M. and Sorensen, J.L. (2009) Maternal Deaths in Denmark 2002-2006. Acta Obstetricia et Gynecologica Scandinavica, 88, 556-562. http://dx.doi.org/10.1080/00016340902897992

[4] Callaghan, W.M. (2012) Overview of Maternal Mortality in United States. Seminars in Perinatology, 36, 2-6.

[5] Chang, J., Elam-Evans, L. and Cynthia, J. (2003) Morbidity and Mortality Weekly Report. CDC, 52, 1-2.

[6] Esscher, A., Högberg, U., Haglund, B. and Essën, B. (2013) Maternal Mortality in Sweden 1988-2007: More Deaths than Officially Reported. Acta Obstetricia et Gynecologica Scandinavic, 92, 40-46. http://dx.doi.org/10.1111/aogs.12037

[7] Farrokh Eslamloo, H., Nanbakhsh, F., Heshmati, F. and Amirabi, A. (2006) An Pidemiological Research of Maternal Mortality in East Azerbaijan 2001-2005. Urmia Medical Journal, 17, 23-31.

[8] Gholami Taramsari, M. (2009) Ten-Year Review of the Causes of Maternal Mortality in Kohgiluyeh Boyer Ahmad Province. Journal of Science and Health, 3, 33-37.

[9] Khajeniian, A., Anaraki, A., Motamed Arya, N., Quaid Mohammadi, Z. and Drnan, M. (2011) Factors Associated with Maternal Death in Bushehr Province in 2000-2007. Journal of Maternal and Neonatal Health, 11-18.

[10] Gumanga, S.K. and Kolbila, D.Z. (2011) Trends in Maternal Mortality in Tamale Teaching Hospital, Ghana. Ghana Medical Journal, 45, 105-110.

[11] Hernandez, B., Langer, A., Romero, M. and Chirinos, J. (1994) The Factors Associated with Hospital Maternal Death in the State of Morelos, Mexico. Salud Pública de México, 36, 521-528.

[12] HMN, UNICEF and WHO (2011) Monitoring Maternal, Newborn Key Progress Indicators. WHO. http://www.who.int/healthmetrics/news.

[13] Golian Tehrani, S.H., Holakouee, K. and Zareii, M. (2009) Investigating Factors Influencing Maternal Deaths in Kurdestan Province in the Years 1999-2002. Life Magazine, 138, 47-54.

[14] Kane, T.T., El-Kady, A.A., Saleh, S., Hage, M., Stanback, J. and Potter, L. (1992) Maternal Mortality in Giza, Egypt: Magnitude, Causes, and Prevention. Studies in Family Planning, 23, 45-57. http://dx.doi.org/10.2307/1966827

[15] Akhlaghi, F., Hamidi, A.K. and Lotfi, N. (2012) Study of Maternal Mortality in the 70 at Imam Reza in Mashhad. Asrar Magazine, 9, 74-80.

[16] Abdollahpour, P., Babaiy, M. and Yarmohammadi, G. (2011) Investigating the Causes of Maternal Deaths from Childbirth in Urban and Rural Areas of Ilam. Health Systems Research Journal, 7, 1-9.

[17] Rshyn, S.H.M. (2009) Demographic Study of Maternal Mortality in the Country Today. MS Thesis, Azad University Central Tehran Branch, Tehran, 152-154.

[18] Montazeri, M. (1999) Review the Causes of the Mortality Project in Kermanshah Province during the Years 1996-1997. Doctoral Dissertation, University of Medical Sciences, Kermanshah.

[19] Nagaya, K., Fetters, M.D., Ishikawa, M., Kubo, T., Koyanagi, T., Saito, Y., et al. (2000) Cases of Maternal Mortality in Japan. Journal of the American Medical Association, 283, 2661-2667. http://dx.doi.org/10.1001/jama.283.20.2661

[20] Maharlouei, N., Zakeri, Z., Mazloomi, E. and Lankarani, K. (2012) Maternal Mortality Rate in Fars Province: Trends and Associated Factors in a Community—Based Survey. Archives of Iranian Medicine, 15, 14-17. 
[21] Mohammadinia, N., Samii Zadeh Toosi, T., Rezaei, M.A. and Rostaei, F. (2013) Prevalence and Influencing Factors of Death for Pregnant Women in the Province of Sistan and Baluchestan in the Years 2002-2009. Journal of Iranian Women, Infertility and Gynecology, 16, 28-34.

[22] Emami Afshar, N., Jalilvand, P., Delaware, B., RadpUyan, L., Azemikhah, A. and Valafar, S.H. (2010) Maternal Death Surveillance. Tandis Publications, Tehran, 14-30.

[23] UNICEF (2008) Progress for Children: A Report Card on Maternal Mortality (No. 7). 45 p. http://www.unicef.org/publications.

[24] WHO (2012) Maternal Mortality. Fact Sheet. No. 34. http://www.who.int/mediacentre/factsheets/fs348/en/.

[25] Zhou, Y.Y., Zhu, J., Wang, Y.P., Dai, L., Li, X.H., Li, M.R., Li, Q. and Liang, J. (2011) Trends of Maternal Mortality Ratio during 1996-2010 in China. Chinese Journal of Preventive Medicine, 45, 934-939.

[26] Farzianpour, F., Nourijelyani, K., Zandiyan, H., Zahirian Moghadam, T. and Moghadam, S.Z. (2014) Accreditation Maternity and Obstetric Services (MOS), Based on the Accreditation Standards of the Joint Commission International (JCI). Health, 6, 2453-2460. http://www.scirp.org/journal/health http://dx.doi.org/10.4236/health.2014.618282 